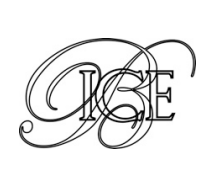

Vadim Grishin*

Ana María Martínez Jerez ${ }^{* *}$

\title{
ARGENTINA Y LAS INSTITUCIONES FINANCIERAS INTERNACIONALES: ¿UN NUEVO COMIENZO?
}

El colapso de la economía argentina en 2002 y la prosperidad vivida por el país en el periodo 2003-2013 al abandonar las directrices del Fondo Monetario Internacional forzaron una revisión de la condicionalidad de los programas del FMI. Los altos precios de los productos básicos y alimentos, principales exportaciones de Argentina, produjeron un golpe de suerte sin precedentes. Sin embargo, a raíz de la crisis financiera mundial de 2008, la economía de Argentina empezó a mostrar su vulnerabilidad al descansar en un modelo económico que en unos años mostraría su incapacidad de crecer. En respuesta al deterioro del entorno exterior y al debilitamiento de las reservas financieras, las autoridades argentinas empezaron a tomar una serie de medidas para volver a los mercados internacionales de capital, mejorar la competitividad nacional, restablecer la estabilidad fiscal y la confianza de los inversores. En este contexto, Argentina es consciente que la normalización de las relaciones con el Grupo del Banco Mundial y el FMI enviará un fuerte mensaje positivo a los socios internacionales y a la comunidad internacional de negocios.

Palabras clave: deuda externa, balanza por cuenta corriente, inflación, recesión, condicionalidad, reformas estructurales.

Clasificación JEL: E3, F4, F5, H3, H6.

«¿No es agradable pensar que mañana es un nuevo día, todavía sin errores?"

L.M. Montgomery

\section{Introducción}

Históricamente, Argentina ha sido uno de los principales socios regionales de las Instituciones de Bretton Woods y el Banco Interamericano de Desarrollo (BID). Ha habido un gran número de discusiones altamente politizadas sobre el legado y

* Economista. Profesor Adjunto. Universidad de Georgetown.

** Técnico Comercial y Economista del Estado.

Versión de julio de 2015. el resultado de esta interacción, especialmente en el contexto de la severa crisis monetaria de Argentina en el período 2000-2002.

El premio Nobel de Economía, Joseph E. Stiglitz, en muchas de sus conferencias y artículos, así como en su polémico libro Cómo hacer que la globalización funcione ha insistido que «Argentina fue el estudiante de matrícula del Fondo Monetario Internacional (FMI), y todos sabemos lo que pasó: Argentina experimentó una crisis de dimensión colosal. Sólo cuando los argentinos rechazaron las recomendaciones del FMI, la economía comenzó a crecer. En el periodo 2004-2006, Argentina creció por encima del 8 por 100 anual» 
Esto parece una generalización injusta y una simplificación excesiva de una situación económica sorprendente tanto para Argentina como para el FMI. EI FMI merece su parte de culpa y debería ser considerado responsable, en parte, de estos eventos dramáticos, porque a lo largo de la década anterior, el FMI estuvo involucrado en el país con cinco acuerdos de financiación sucesivos. No obstante, había otros actores también involucrados que tenían la responsabilidad última de la política económica de Argentina.

Con este telón de fondo, el objetivo de este artículo es presentar las lecciones aprendidas por el FMI en el caso de Argentina; los motivos que llevaron a este país del colapso económico a los años de bonanza en la primera década de 2000; los fallos del modelo económico actual argentino que empujan a sus autoridades a acercarse nuevamente a las Instituciones de Bretton Woods y diferencias y similitudes entre Argentina y Grecia. El artículo concluye con una reflexión sobre el futuro de Argentina.

\section{Lecciones aprendidas por el FMI}

La decisión del FMI de proporcionar préstamos a Argentina en 2001, y el posterior incumplimiento del pago de su deuda, tuvieron amplias repercusiones en las prácticas de concesión de préstamos del FMI. Esta situación sirvió como catalizador final para un examen detallado de la política de acceso excepcional del FMI que inicialmente fue diseñada para ser muy flexible en función de las «circunstancias excepcionales".

La Oficina de Evaluación Independiente (OEI), creada en 2001 para llevar a cabo evaluaciones independientes y objetivas de las políticas y las actividades del FMI, emitió un informe, que analizaba el papel del FMI en Argentina durante 1991-2001, centrándose especialmente en el periodo de gestación de la crisis a partir de 2000 hasta el impago soberano a principios de 2002.

Desde entonces el FMI ha revisado periódicamente la relación entre su marco de concesión de préstamos y la vulnerabilidad de la deuda soberana de un país. Los componentes claves de este marco se modificaron de nuevo en 2010 , pero el impulso inicial para el ajuste se recibió de los acontecimientos de 2002 que sirvieron como modelo para explorar el cambio específico para hacer las prácticas de concesión de préstamos más calibradas a las situaciones de deuda de los países miembros.

La OEI admitió que la vigilancia y la condicionalidad de los programas del FMI fueron «obstaculizados por las debilidades de los análisis y las limitaciones de los datos». La falta de una fuerte condicionalidad estructural «tuvo el desafortunado resultado de obligar a que el FMI siguiera comprometido con Argentina, cuando la evidente falta de avances sustantivos en las reformas estructurales debería haber puesto fin al programa». EI FMI dejó de proporcionar financiación a Argentina cuando el país no cumplió con sus objetivos de déficit. La población argentina se apresuró para retirar su dinero de los bancos, pero el Gobierno congeló los depósitos, provocando los consiguientes disturbios y una oleada de inestabilidad política (Argentina tuvo tres presidentes en cuatro días). La economía argentina cayó en depresión.

En virtud de los resultados y lecciones aprendidas de esta experiencia argentina del FMI, la OEI elaboró un conjunto detallado de recomendaciones. La respuesta de los evaluadores a la cuestión de vital importancia que debía estar presente en esa interacción bilateral fue bastante ambigua. Por un lado, los evaluadores destacaron la importancia de que Argentina se involucrara y aceptara el buen hacer del FMI. Por otro lado, los evaluadores introdujeron una condicionalidad importante en la aplicación de este principio, pero no debía dar lugar a políticas equívocas o excesivamente débiles. Ante el hecho de que una debilidad institucional está por lo general muy arraigada en los sistemas políticos de los países emergentes, el FMI tenía que imponer la condicionalidad estructural de las próximas reformas, que no podía ser sustituida por la mera participación e involucración de Argentina en el diseño del programa. 
La OEI se centró también en la velocidad de las acciones necesarias para resolver la crisis. Cualquier retraso podía aumentar significativamente su coste final a través de una mayor pérdida de producción, fuga de capitales adicional y erosión de la calidad de los activos en el sistema bancario.

Por el lado monetario, se reconoció que el tipo de cambio argentino, con el peso vinculado a la paridad del dólar desde 1991 hasta enero de 2002, se hizo incompatible con otras políticas.

Se prestó especial atención a las políticas fiscales, que podían ayudar a estabilizar las condiciones económicas y suavizar los shocks de la actividad económica en el período de crisis. Es por eso que las medidas fiscales debían ser sensibles a los desequilibrios fiscales año a año y al stock global de deuda pública.

Un marco fiscal que promueva la estabilidad fiscal a través del ciclo económico puede fomentar un crecimiento más estable y elevado, al mismo tiempo que apoya la sostenibilidad de la deuda. El nivel de deuda sostenible depende de las características económicas de un país. Cuando existen preocupaciones bien fundadas sobre la sostenibilidad de la deuda y del tipo de cambio, no es razonable esperar una reversión voluntaria de los flujos de capital. Sólo una reestructuración de la deuda que lleve a la reducción del valor actual neto (VAN) de los pagos de la deuda o, si se cree que la deuda es sostenible, un amplio paquete de financiación por parte del sector público tiene la posibilidad de revertir la dinámica de la deuda desfavorable. En este sentido, el FMI desarrolló posteriormente un concepto acerca de la necesidad de restablecer tanto la confianza de los inversores como la capacidad de un país para recuperar el acceso a los mercados de capital.

Al mismo tiempo, cualquier operación de reestructuración de la deuda impone unos costes que deben sopesarse frente a los costes de retrasar la reestructuración, de lo contrario los problemas para un cliente pueden agravarse, poniendo los recursos propios del FMI en mayor riesgo.

La conclusión general de la OEI fue bastante sencilla: el proceso de toma de decisiones del FMI debía mejorar en términos de análisis de riesgos, responsabilidad y previsibilidad. Cuando los problemas de balanza de pagos no se pueden resolver en un plazo razonable (medio plazo), puede ser mejor no aceptar un acuerdo. A pesar del trauma, la economía argentina se estabilizó en 2002.

\section{Años de bonanza (2003-2013): logros y defectos}

En la última década, aproximadamente dos tercios de las economías de mercados emergentes y en desarrollo experimentaron un crecimiento sin precedentes. Estas economías sólo conocieron un revés a corto plazo durante la crisis financiera. Este extraordinario ciclo expansivo se debió en parte a un fuerte crecimiento de China, aunque otras economías de países emergentes también aumentaron sustancialmente su PIB en casi un 5 por 100 en promedio en la década de 2000 , lo que implicó una media de crecimiento del 1 por 100 mayor que la registrada durante los 20 años anteriores.

Las economías de mercados emergentes vivieron un contexto externo favorable que apoyó su crecimiento, con un comercio mundial creciente potenciado por la liberalización financiera y comercial; la mejora de las condiciones financieras impulsadas por tipos de interés a la baja; la reducción de la deuda pública y externa y los diferenciales soberanos y unos precios de las commodities sostenidamente altos. Las recientes «Perspectivas del FMl» ponen el acento en los siguientes determinantes de este período inusual de desarrollo de las economías de mercados emergentes:

- La agresiva expansión de las cadenas de valor mundial y regional, que estimulan la transferencia de conocimiento y tecnología.

- El trasvase de recursos a los sectores de mayor productividad, como resultado de la reubicación y la creciente inversión extranjera directa.

- La mayor diversificación, expansión de las industrias no alimentarias y servicios múltiples. $\triangleright$ 
Muchos mercados emergentes podrían haber aplicado algunas reformas estructurales que tanto se necesitaban para mejorar su competitividad y crecimiento de productividad. El superávit por cuenta corriente y las abultadas reservas de divisas habían abierto un margen de maniobra monetaria y fiscal que reinaba en estas economías. Se propuso la teoría de la disociación entre los grandes mercados emergentes, especialmente los países BRIC (Brasil, Rusia, India y China) y las economías desarrolladas. Como siempre sucede, la realidad resultó ser más complicada. Una crisis financiera mundial puso de manifiesto que la demanda de los mercados desarrollados, en particular a través de las cadenas de suministro globales, siguen teniendo una importancia crítica para el desarrollo de las economías de mercados emergentes.

Vale la pena mencionar que durante 20032013 el crecimiento del PIB de Argentina fue incluso superior a los indicadores promedio de las economías de mercados emergentes. EI PIB de Argentina creció a un ritmo medio del 6 por 100 anual frente a una tasa media anual de crecimiento del 2 por 100 lograda durante el periodo 1991 2002. La industria en Argentina creció a una tasa anual del 9 por 100, alcanzando un crecimiento récord del 17 por 100 la fabricación de automóviles. La producción de automóviles se multiplicó por más de cuatro, pasando de 200.000 unidades en 2003 a 826.000 unidades en 2011, la mitad de los cuales eran para la exportación.

Una de las razones de tal "salto económico" fue que las exportaciones argentinas crecieron como consecuencia del aumento de la competitividad a causa de la depreciación de la moneda y la aceleración económica de sus principales socios comerciales. La «bonanza de los productos básicos" y los altos precios de los alimentos produjeron un golpe de suerte sin precedentes. La dirección del comercio también se desplazó. La soja se convirtió en el principal producto de exportación (17,5 por 100 de la exportación total del país), con China como comprador principal. Todos los esfuerzos de los productores argentinos para mejorar su posición en la cadena global de valor a través de la fabricación local de aceite de soja no tuvieron éxito. Los productos primarios representaban el 85 por 100 de las exportaciones argentinas a China. Por el contrario, Brasil se convirtió en el mayor importador de bienes manufacturados de Argentina, comprando más del 80 por 100 de las exportaciones de automóviles argentinos.

La demanda interna fue apoyada principalmente por el consumo interno y la inversión privada, que aumentó hasta el 20 por 100 . Mientras que la inversión pública se estancó y se mantuvo en un nivel relativamente bajo de 3,6 por 100; la inversión en su conjunto alcanzó de forma sostenida un nivel promedio de 21 por 100 del PIB entre 2001 y 2012. Este porcentaje fue un 2,8 por 100 más alto de lo que fue entre 1993 y 2001.

Las entradas netas de inversión extranjera directa (IED) alcanzaron un nivel récord de 15.300 millones de dólares en 2012 (Gráfico 1) y la IED acumulada del país creció de 17.000 millones a 57.000 millones de dólares en el período 20052010. El sector petrolero fue el principal receptor de IED (22,5 por 100), seguido de la extracción de minerales, industria química y sector financiero privado.

Por país de origen, los inversores estadounidenses alcanzaron una posición de liderazgo con casi 13.000 millones de dólares de inversión directa acumulada en 2013, seguido por Holanda con 9.400 millones de dólares. España perdió su liderazgo a largo plazo, pasando a la tercera posición con 9.300 millones de dólares de inversión directa después de la polémica nacionalización de la parte de propiedad española de YPF.

Las inversiones y los préstamos que han registrado un rápido crecimiento en Argentina proceden de los países BRIC, principalmente China (Tabla 1). Sinopec Group ${ }^{1}$ compró una unidad de petróleo y gas argentina de Occidental Petroleum Corporation por 2.450 millones de dólares en 2010. Occidental Argentina tenía reservas probadas $\triangleright$

\footnotetext{
1 Business Development Petroleum Engineering China Petrochemical Corporation.
} 


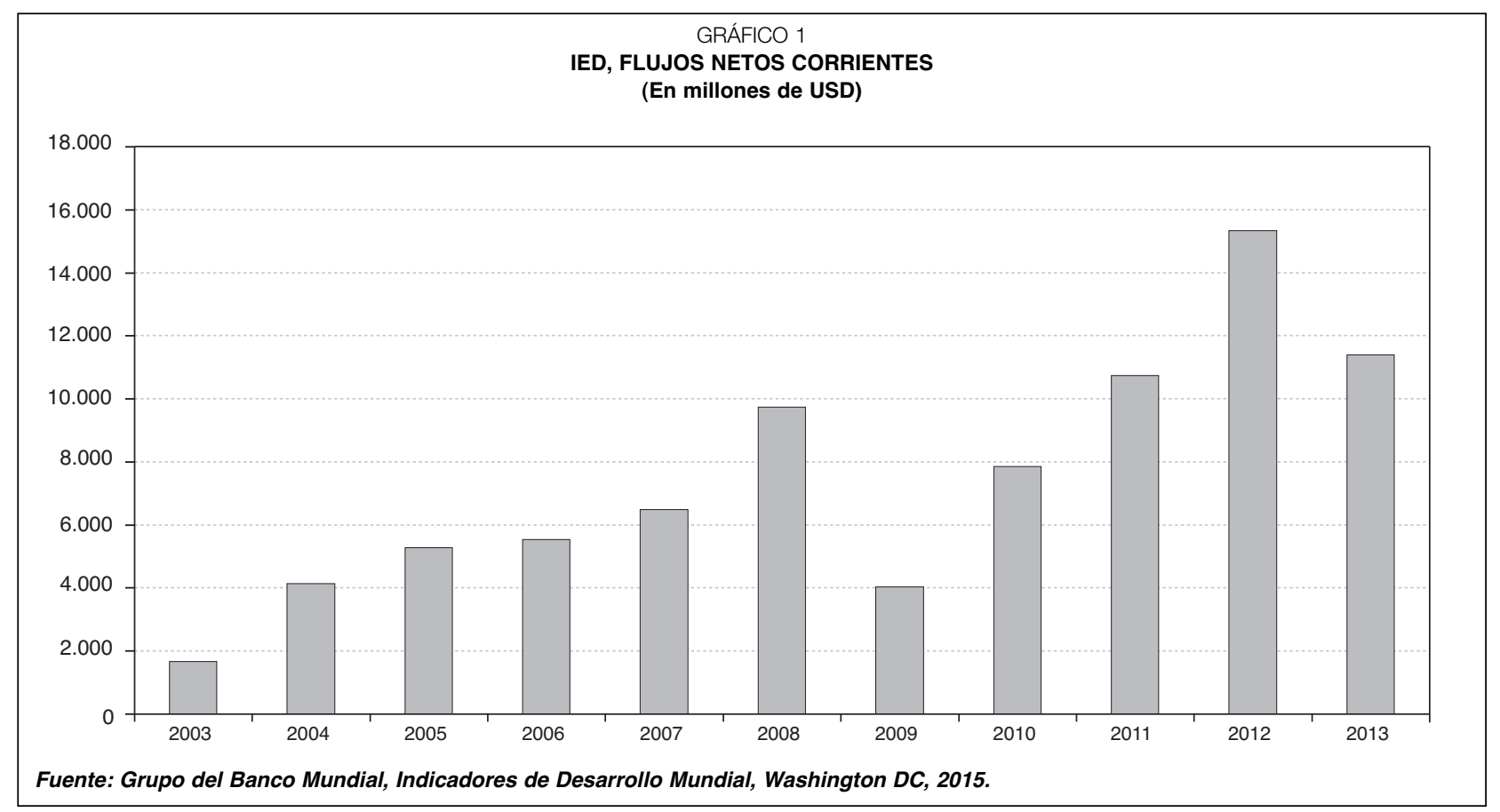

\begin{tabular}{l|lr}
\multicolumn{2}{c}{ TABLA 1. ACUERDOS DE PRÉSTAMOS DE CHINA CON ARGENTINA } \\
(Millones de USD)
\end{tabular}

brutas de 393 millones de barriles equivalentes de petróleo e intereses en 23 concesiones de producción y exploración en el país. Mientras que CNOOC Group ${ }^{2}$ compró una participación del 50 por 100 en el holding argentino Bridas por 3.100 millones de dólares. Esta operación dio acceso a CNOOC Group a los activos e inversiones de Bridas, incluyendo su participación del 40 por 100 en Pan American Energy, el segundo mayor productor de combustibles fósiles de Argentina, así como los activos de petróleo y gas de Bridas en Chile y Bolivia.

La mayor compañía de productos agrícolas y alimentos de China, COFCO Corporación, adquirió el 51 por 100 del grupo de comercialización de productos básicos y agrícolas de Países Bajos,

\footnotetext{
${ }^{2}$ China National Offshore Oil Corporation.
}

Nidera, por unos 1,2 millones de dólares en marzo de 2014. La sucursal más grande de Nidera está localizada en Argentina con una capacidad de almacenamiento y red logística de 5,5 millones de toneladas. La soja, trigo y maíz son los principales productos comercializados por Nidera. Muchos agricultores locales expresaron su preocupación respecto a esta compra debido a una potencial concentración de mercado.

COFCO también compró una participación mayoritaria en Noble Group (basado en HongKong) que gestiona la cadena de suministro internacional de recursos agrícolas, energía, metales y minerales, por 1.500 millones de dólares en 2014. COFCO planea formar una empresa conjunta entre Nidera y Noble Group, para vincular su negocio de procesamiento y distribución de cereales en China con abastecimiento de granos $\triangleright$ 


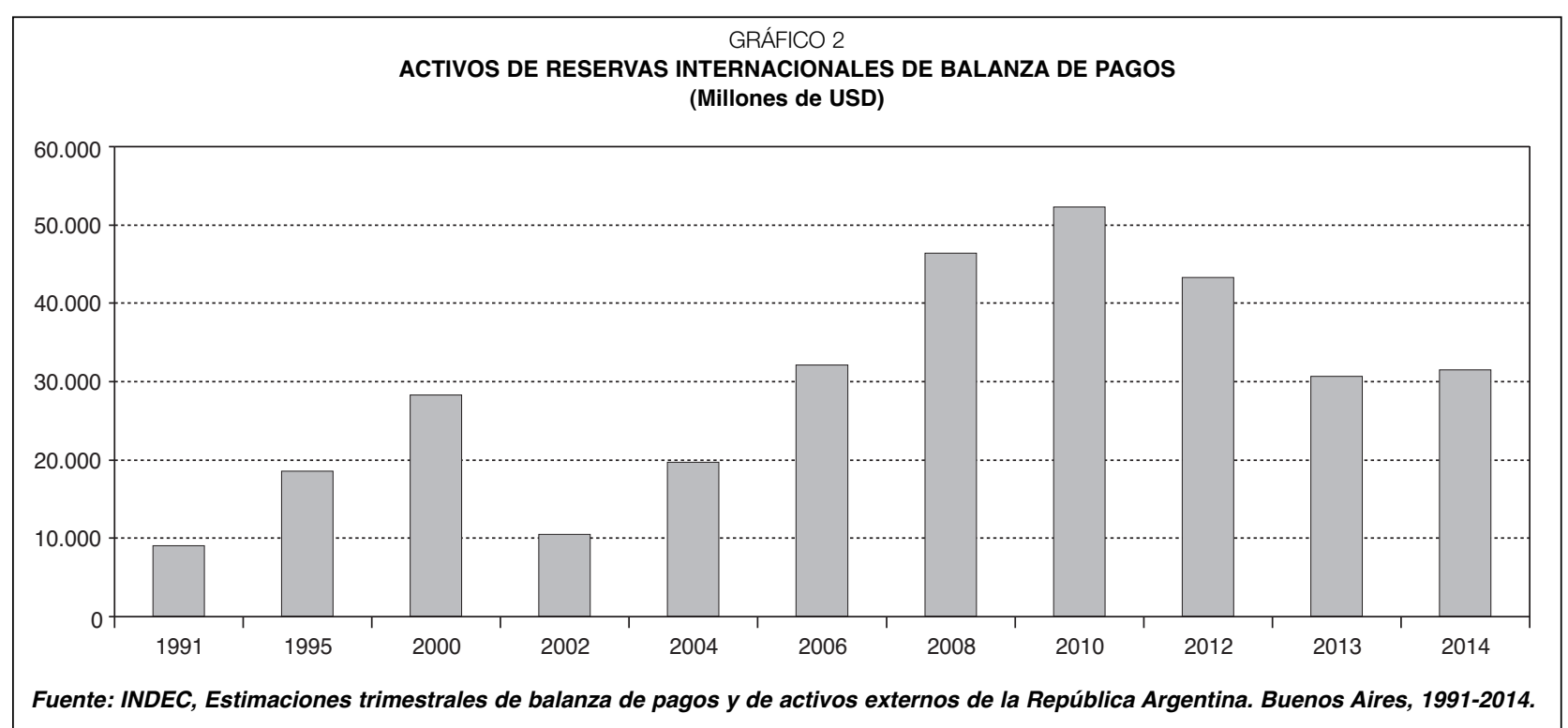

y comercio de armas en América Latina y fortalecer, de esta manera, su posición de mercado en todo el mundo.

Sin embargo, la participación de la IED de Asia (principalmente de China) se mantuvo relativamente baja en Argentina (2,6 por 100 del total) en 2014, frente al 10 por 100 en Brasil y más del 14 por 100 en Ecuador. Nadie puede sobreestimar el papel de la IED en el modelo económico argentino, ya que su participación en el PIB es de alrededor del 2 por 100; sin embargo, nadie debe subestimar el impacto de la IED. Investigadores de la Comisión Económica para América Latina y el Caribe (CEPAL) observaron una diferencia importante entre la IED de los años noventa y la década del 2000 en Argentina. Las fusiones y adquisiciones dominaron en los años noventa generando un efecto de exclusión (crowding out). Desde 2004, una nueva oleada de IED ha incentivado la creación de clusters industriales, ha ayudado a aumentar la productividad, y ha abierto nuevas oportunidades para hacer frente a los desequilibrios estructurales. La industria del automóvil ha absorbido tecnología moderna y conocimientos técnicos, y productores extranjeros de petróleo y gas natural han traído nuevos equipos, mejorando el rendimiento de los pozos.

En la última década, el crecimiento económico y social ha tenido un carácter inclusivo. En las áreas metropolitanas se han creado 3,7 millones de puestos de trabajo. El nivel de desempleo ha disminuido del 20 al 6,9 por 100 entre 2002 y 2012. La mejora del mercado laboral ha contribuido de manera significativa a la reducción de la pobreza del 31 por 100 en 2004 al 10,8 por 100 en 2013 y la pobreza extrema se ha reducido del 6,3 al 1,3 por 100 en el mismo período. El coeficiente de Gini se ha reducido de 50,2 por 100 en 2004 a 42,5 por 100 en 2012 y la clase media ha crecido del 34 al 53 por 100 de la población entre 2000 y 2011 lo que ha marcado mejoras en el área de prosperidad compartida. Sin embargo, más del 40 por 100 de la población argentina se mantiene en riesgo de caer en la pobreza.

Hasta la crisis financiera mundial de 2009, el crecimiento de las exportaciones y la mejora de los ingresos fiscales llevaron a superávits fiscales y externos, permitiendo acumular reservas internacionales a Argentina que alcanzaron el mayor nivel de todos los tiempos en 2010 (52.000 millones de dólares) (Gráfico 2).

En 2006 Argentina canceló anticipadamente su deuda con el FMI en un único pago. Según el Banco Central de la República Argentina, la deuda externa del país se redujo de 160.000 millones de dólares en 2011 a 115.700 millones de dólares en 2014 (Gráfico 3). Pero la deuda externa bruta total, incluyendo los acreedores que no $D$ 


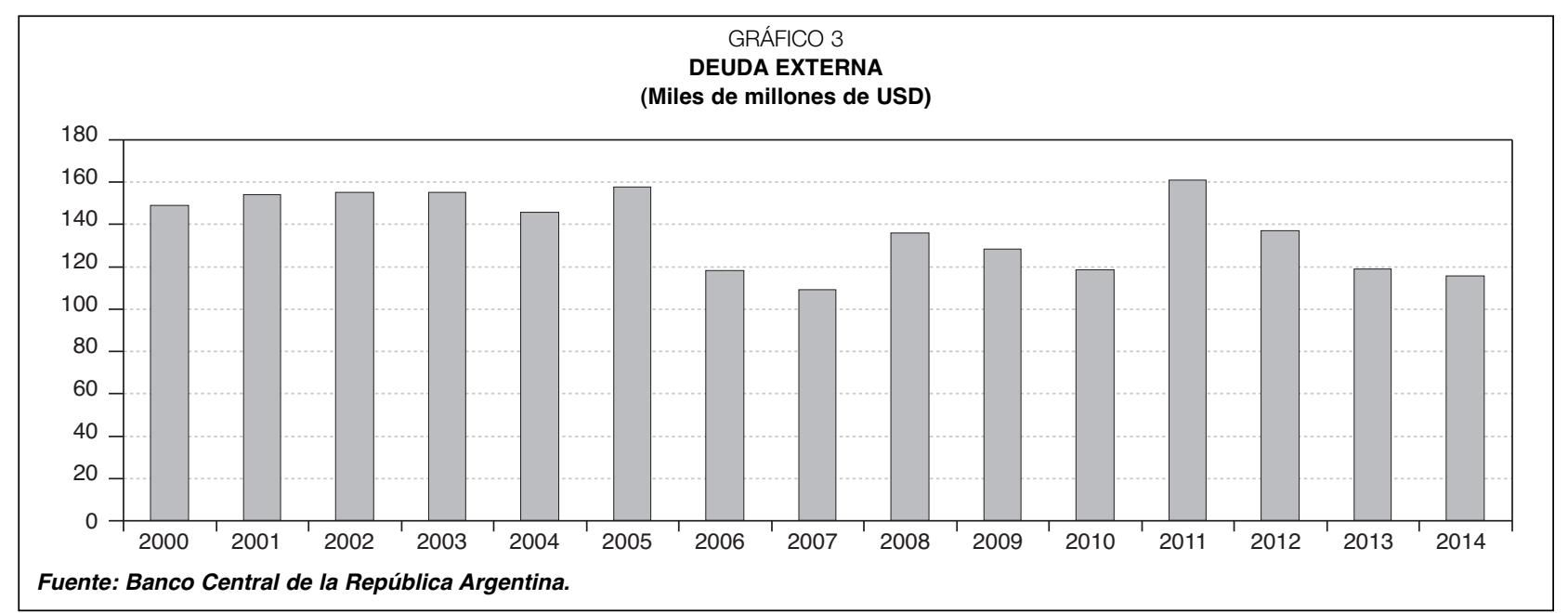

entraron en el canje de deuda (holdouts), aún se mantiene prácticamente en el mismo nivel de 159.000 millones de dólares (aproximadamente el 30 por 100 del PIB). La deuda pública federal bruta alcanzó casi 250.000 millones de dólares en 2014 (46 por 100 del PIB).

Cuando la presidenta Cristina Fernández de Kirchner fue reelegida en 2011, el Gobierno introdujo un control estricto de divisas con el fin de tratar de acumular reservas y limitar la salida de capitales. Como resultado, la caída de salidas de capital se multiplicó por seis pasando de 21.500 millones de dólares en 2011 a 3.400 millones de dólares en 2012 , pero esta medida no añadió confianza a la moneda nacional. Las políticas monetaria y fiscal fueron expansivas y alimentaron la inflación. En este ambiente proinflacionista, las autoridades acentuaron aún más la regulación administrativa de precios sobre bienes y servicios (congelación de precios), así como el control sobre las importaciones y operaciones en divisas. El populismo económico ha continuado en forma de amplios subsidios a la energía, transporte público y alimentos (alcanzando el 5 por 100 del PIB en 2013) y de subida de los gastos sociales (21 por 100 del PIB), principalmente pensiones, cargando el presupuesto público y, por ende, deteriorando la posición fiscal del Gobierno.

El aumento de las intervenciones en la economía ha incluido medidas de fuerte proteccionismo, la renacionalización de algunas empresas privatizadas previamente (tal es el caso de Aerolíneas
Argentinas en 2008, YPF en 2012) y de los fondos de pensiones privados (2008) que desafiaron la confianza de los inversores en el Estado de Derecho, la estabilidad de las normas reguladoras y la eficiencia de la aplicación de los derechos de propiedad.

La puntuación de Argentina en materia de libertad económica ha caído en picado en los últimos 5 años pues el país ocupa el lugar 27 de 29 en la región de América Latina. Mientras que su puntuación en competitividad global sigue siendo baja (104 de 144), su puntuación en índices tan importantes como el efecto de los impuestos sobre los incentivos para invertir y trabajar (144), las barreras comerciales (143), la IED y la transferencia de tecnología (143), los procedimientos para iniciar negocios (139), los derechos de propiedad (138), la protección de la propiedad intelectual (136), la accesibilidad a los servicios financieros (138) han sido aún peores (19). El ranking Doing Business del Banco Mundial (124 de 189) también ha puesto al país por debajo del promedio de la región (100). Argentina está en una categoría baja en indicadores significativos, tales como manejo de permisos de construcción (181), el pago de impuestos (170), y el registro de la propiedad (119). Es cierto que cualquier índice internacional no puede medir y reflejar todos los aspectos del ambiente de negocios, pero las posiciones más retrasadas de Argentina en muchas encuestas empresariales importantes muestra claramente que las políticas regulatorias $\square$ 
existentes no crean incentivos económicos ni fortalecen la iniciativa empresarial o la competitividad.

Argentina ha permanecido fuera de los mercados internacionales de bonos después de que dejara de pagar 92.000 millones de dólares de principal de su deuda externa durante la crisis financiera en diciembre de 2001. Las reestructuraciones de deuda en 2005 y 2010 no recibieron el apoyo de todos los acreedores, a pesar de que Argentina reestructuró el 93 por 100 de su deuda externa con un descuento del 70-75 por 100. Un grupo minoritario de los llamados acreedores que no entraron en el canje de deuda (holdouts) liderados por los fondos buitre rechazaron cualquier reducción (haircut) y en 2011 presentaron una demanda contra Argentina en la Corte del Distrito Sur de Nueva York. Esta situación ha creado una ambigüedad adicional para los inversores que temían que todo el dinero recaudado se congelaría por demandas de los acreedores que no entraron en el canje de deuda. En este contexto, la prima de riesgo de impago y riesgo de mercado de Argentina alcanzó un nivel muy elevado de nuevo.

La situación se deterioró aún más cuando en junio de 2014, la Corte Suprema de los Estados Unidos se negó a escuchar la apelación de Argentina a las decisiones de los tribunales federales de New York que concluyeron que Argentina había violado la cláusula pari passu en los bonos impagados (defaulted bonds) y se le prohibió hacer pagos futuros de los bonos reestructurados a menos que a los acreedores que no entraron en el canje de la deuda se les pagara en su totalidad. Desde entonces los pagos por parte de Argentina de esos bonos reestructurados de derecho extranjero han sido completamente bloqueados y hay una falta de claridad sobre los futuros pagos de bonos reestructurados denominados en moneda extranjera en todas las jurisdicciones. Cualquier decisión es probable que se posponga hasta que un nuevo presidente electo en las próximas elecciones de octubre de 2015 ocupe su despacho en la Casa Rosada.

\section{4. ¿Un punto de inflexión hacia «años de vacas flacas»?}

A raíz de la crisis financiera mundial de 2008, la economía de Argentina entró en un período de vulnerabilidad y comenzó a desacelerar. Después de un crecimiento casi cero en 2009 , creció un 9,1 por 100 en 2010 y un 8,6 por 100 en 2011, pero la recuperación económica no era sostenible. Se trató de un pico de recuperación temporal que terminó rápidamente. Tan pronto como la demanda interna y externa se debilitaron, el crecimiento se desaceleró drásticamente al 0,9 por 100 en 2012; subió al 2,9 por 100 en 2013 y volvió a caer al 0,5 por 100 en 2014. De acuerdo con la previsión del FMI, el PIB podría contraerse en 2015 y estar cerca de cero en 2016. El alivio temporal a principios de 2015 (Gráfico 4) se explica por la reducción de la factura de importación de petróleo y precios de energía más bajos, y por inversiones públicas adicionales en la industria de la construcción a través del programa de préstamos de vivienda subsidiada por el Gobierno (PROCREAR). Sin embargo, todo ello es poco probable que pueda evitar la caída en recesión de Argentina. Se espera que los precios del petróleo sean bajos pero existe un alto nivel de incertidumbre y volatilidad, lo que puede afectar a las inversiones en proyectos de gas y aceite de esquisto. El gasto público no puede ser elevado porque las reservas financieras se han evaporado y el Gobierno ha visto restringida su capacidad de pedir prestado a nivel nacional e internacional.

La disminución del crecimiento acompaña a la alta inflación, lo que es un síntoma peligroso de estanflación a pesar de que el nivel de desempleo en Argentina sigue siendo moderado (7 por 100 a finales de 2014). Según el Instituto de Finanzas Internacionales, la tasa de inflación se situó en 26,4 por 100 en 2013, 40,6 por 100 en 2014 (mientras el Instituto Nacional de Estadística y Censos (INDEC) de Argentina informó que la inflación fue del 23,9 por 100 en 2014); la inflación será del 35 por 100 en 2015 y del 41,8 por 100 el próximo año. Las proyecciones $\triangle$ 


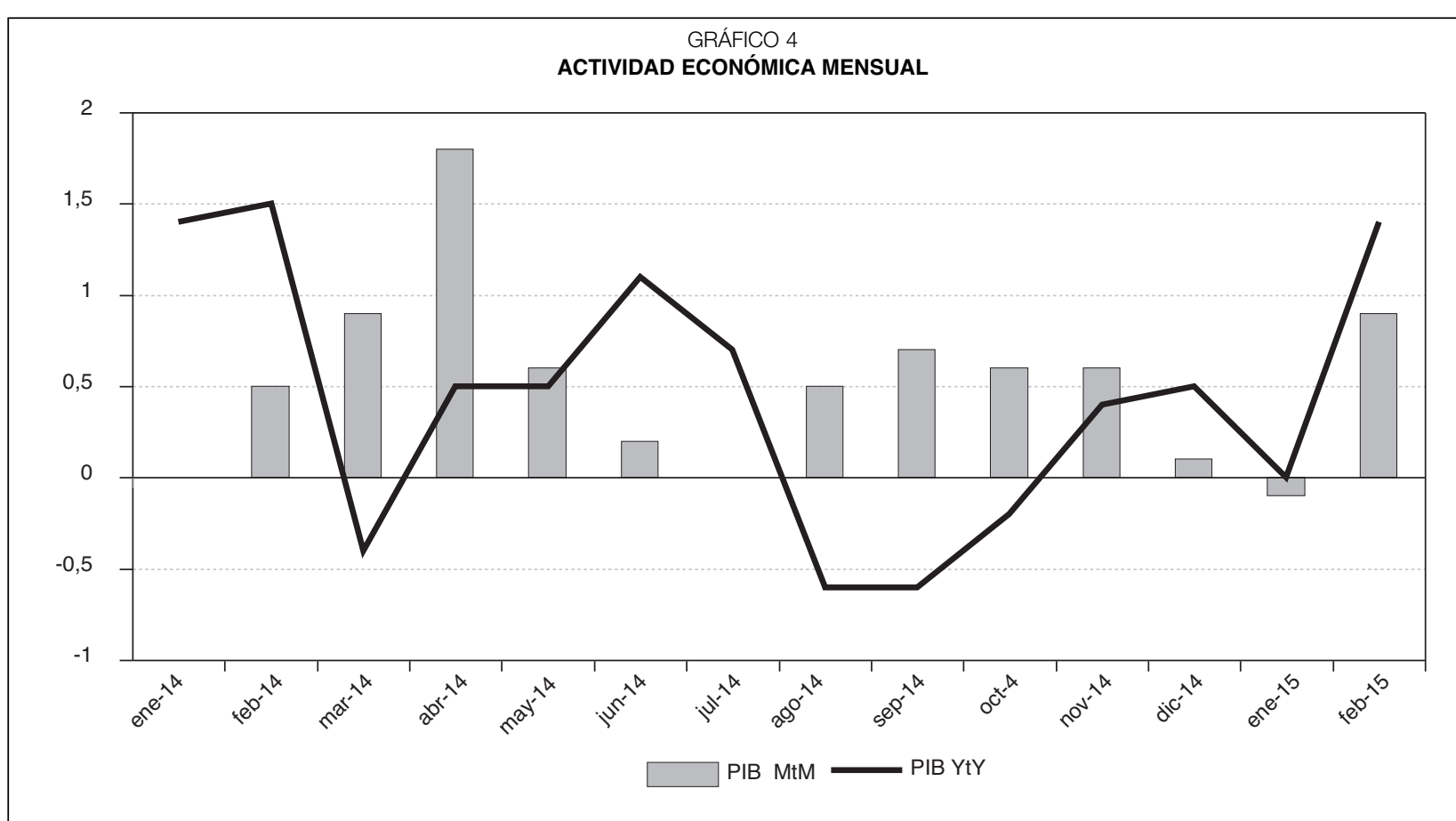

Fuente: Instituto Nacional de Estadística y Censos. Estimador mensual de actividad económica. Buenos Aires, 24 de abril de 2015.

\begin{tabular}{|c|c|c|c|}
\hline \multicolumn{4}{|c|}{$\begin{array}{c}\text { TABLA } 2 \\
\text { PRECIOS DE CONSUMO. PROYECCIONES }\end{array}$} \\
\hline Año & 2015 & 2016 & 2020 \\
\hline Cambio porcentual anual & 18,6 & 23,2 & 19,1 \\
\hline
\end{tabular}

del FMI sobre el crecimiento de precios al consumo son más prudentes, pero siguen siendo altas (Tabla 2).

Los riesgos de recesión pueden verse en diferentes áreas:

- El sector financiero. El crecimiento del crédito ha sido anémico y los depósitos bancarios han caído como resultado de tipos de interés negativos en términos reales. Los mercados financieros y de capitales tienen poca profundidad y el número de inversores institucionales es limitado. La financiación a largo plazo y de transacciones comerciales están subdesarrolladas. Una gran cantidad de transacciones se liquida en efectivo. El sector empresarial se apoya en los ingresos retenidos para financiar inversiones. Las inversiones brutas en capital fijo se han contraído en un 41 por 100 en 2014. El movimiento divergente del tipo de cambio respecto al dólar y las monedas de los principales socios comerciales ha complicado aún más la situación. Por un lado, la fuerte apreciación del dólar estadounidense ha venido presionando al alza el peso argentino, mientras que el real brasileño ha caído drásticamente. La debilitada competitividad de Argentina ha deprimido las exportaciones. Por otro lado, las altas expectativas de devaluación rápida revelan una confianza débil en la moneda local. Como resultado, se ha producido una huida creciente de capitales hacia monedas fuertes, y los stocks de producción agrícola e industrial han alcanzado niveles récord. El peso está cayendo bajo una fuerte presión.

- La agricultura. El volumen de producción y exportaciones es alto pero los precios han experimentado una fuerte caída. Por ejemplo, los precios de la soja y el maíz han caído un 40 y un 25 por 100, respectivamente, desde abril 2014. Los $\triangleright$ 


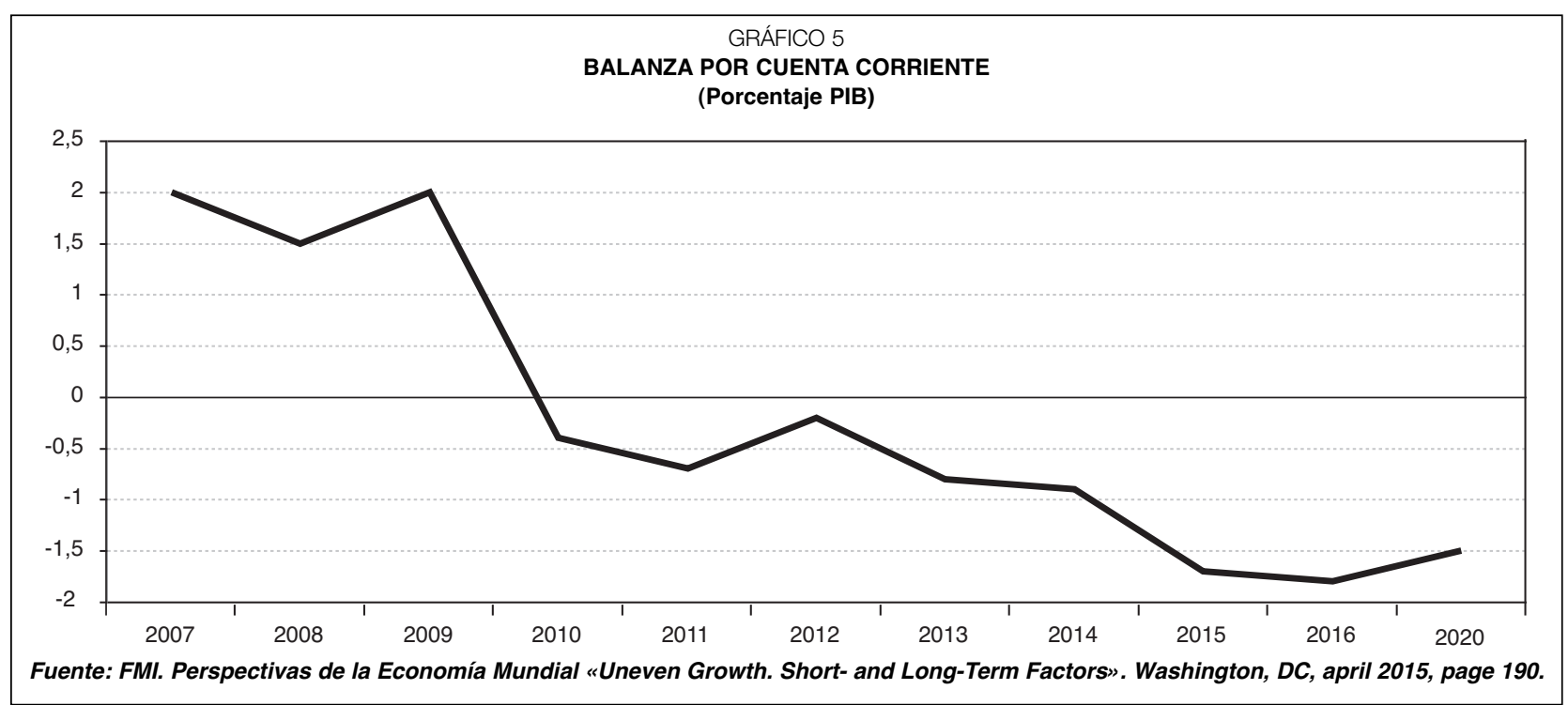

precios de los cereales probablemente seguirán siendo bajos, y podrían disminuir aún más debido a la debilidad de la demanda externa y la fuerte competencia de los productores no tradicionales.

- La industria automotriz. Es una de las fuerzas económicas de Argentina; ha sido duramente golpeada, tanto por la menor demanda en el país como por las menores ventas a su principal socio comercial, Brasil, que absorbe el 21 por 100 de las exportaciones totales argentinas. A pesar de las medidas de estímulo, la producción de vehículos y las ventas en el primer trimestre de 2015 han caído un 30 por 100 respecto al año anterior.

- La construcción. La actividad ha caído debido a la disminución de la construcción de infraestructuras y carreteras.

- Las exportaciones. Han disminuido un 12 por 100 hasta 71.900 millones de dólares en 2014, mientras que el superávit comercial ha alcanzado su nivel más bajo desde 2001 (6.700 millones de dólares) frente a un superávit de 8.010 millones de dólares en 2013, y 12.400 millones de dólares en 2012.

- Posiciones fiscales. Se han debilitado transformándose el superávit en déficit. El déficit fiscal del gobierno federal alcanzó el 2,5 por 100 en 2014 siendo cubierto por el Banco Central.

- El déficit por cuenta corriente. Ha aumentado desde el 0,4 por 100 del PIB en 2010 al 0,9 por 100 en 2014, y las proyecciones para 2015 y
2016 son del orden del 1,7 y 1,8 por 100 , respectivamente (Gráfico 5).

Esto significa que el Gobierno no va a ser capaz de confiar en su superávit para aumentar la posesión de dólares. Argentina va a sufrir escasez de divisas que limitarán el crecimiento económico de forma severa debido tanto a los elevados pagos de deuda a corto plazo previstos para los próximos años, como a la caída de los ingresos por exportaciones. Todo ello limitará inevitablemente las importaciones, el 70 por 100 de las cuales son bienes de capital e insumos intermedios. El Banco Central de Argentina tiene reservas para cubrir cerca de cinco meses de importaciones (aproximadamente $\mathbf{3 0 . 0 0 0}$ millones de dólares) exclusivamente a través de swaps en renminbi a corto plazo y entradas limitadas de divisas procedentes de las instituciones financieras internacionales (IFI). La contracción de las reservas internacionales en Argentina crea riesgos macroeconómicos significativos debidos tanto a que el país no tiene acceso a los mercados de capitales internacionales como a la aplicación de un conjunto de políticas para reducir el déficit por cuenta corriente.

\section{5. ¿Qué ocurrirá más allá de 2015 en Argentina?}

Uno de los principales inconvenientes para el desarrollo de Argentina es su contracción económica $\triangleright$ 
y la caída acentuada de su estabilidad financiera. La reducción temporal de la actividad económica no es un gran problema. No obstante, muchos de los problemas han surgido debido al estancamiento a largo plazo. El actual modelo económico no genera un crecimiento sostenible. En la última década, las fortunas económicas se hicieron y descansaron en una demanda externa creciente de las principales exportaciones argentinas y en un fuerte consumo local; en parte, las políticas de redistribución contribuyeron a ello. Esta ecuación ya no funciona correctamente y la regulación administrativa está casi agotada con el aumento de la ineficiencia de las políticas que aplica. Argentina se enfrenta a una nueva y dura realidad económica con una combinación única de shocks estructurales, coyunturales y externos (internacionales y regionales). Esta combinación de shocks complica la tarea de recuperación.

En primer lugar, Argentina se ve afectada por una crisis estructural que ha impactado a varios países latinoamericanos, entre ellos Brasil. El problema estructural de Argentina es su gran reto, incluso más que la fuerte caída de los precios mundiales de los alimentos. Durante los últimos 15 años, Argentina ha fracasado en lanzar unas reformas institucionales profundas y sostenidas, y esto ha dado lugar a una decadencia institucional y a una disminución en la tasa de crecimiento potencial de la economía. La desaceleración impulsada por factores estructurales es más difícil de revertir al requerir tiempo y voluntad política para modificar las políticas y ajustar las normas.

En segundo lugar, hay una cuestión de ciclo económico en la economía de Argentina. Una desaceleración de las inversiones se ha visto agravada por el litigio de deuda soberana respecto a los acreedores que no participaron en el canje de la deuda. Se espera que la vuelta de Estados Unidos a una política monetaria convencional deteriore las condiciones financieras y monetarias en América Latina, y las perspectivas de Argentina para atraer dinero barato y a largo plazo de los mercados internacionales de capital continúa sin estar clara, incluso aunque se encontrara una solución a los acreedores que no participaron en el canje de deuda (holdouts). Bajo la presión inflacionista, una política monetaria contractiva se hace necesaria. El margen de maniobra para llevar a cabo medidas anticíclicas para compensar la desaceleración del crecimiento también se ve limitado por la constreñida situación fiscal y la complejidad de la movilización de ingresos con la "nueva norma" de los precios de los alimentos. En estas circunstancias, la consolidación fiscal dolorosa es casi inevitable para fortalecer la balanza por cuenta corriente.

En tercer lugar, hay shocks externos, incluyendo la caída de los precios mundiales de los alimentos, y un más bajo crecimiento de los socios comerciales de lo esperado. América Latina se enfrenta a una probable nueva «realidad mediocre» de larga duración.

En este contexto, es muy difícil encontrar la combinación correcta de políticas, ya que todos los temas están interconectados y el espacio de actuación de las políticas es limitado. El ejemplo más notable de esta complejidad se manifiesta en el sector energético. A pesar de los enormes recursos energéticos, Argentina se ha desplazado rápidamente del grupo de países exportadores de energía al grupo de países importadores. La producción total de energía primaria se redujo de 3.822 cuatrillones de BTU (British Thermal Unit), en 2006 a 3.111 cuatrillones de BTU en 2012; mientras que el consumo aumentó de 3.304 cuatrillones de BTU a 3.665 cuatrillones de BTU en el mismo período. Argentina importó 18.400 millones de kilovatioshora en 2014, casi un aumento del 80 por 100 respecto a las importaciones de energía eléctrica en 2013, para satisfacer la demanda nacional de electricidad. La producción de petróleo del país se ha contraído en un tercio desde su máximo alcanzado en 1998. A pesar de tener 11,1 trillones de pies cúbicos de reservas probadas de gas natural, y la segunda mayor cuenca de gas de esquisto en el mundo en «Vaca Muerta», con unos 308 trillones de pies cúbicos de reservas de gas de esquisto estimadas, la producción de gas natural de Argentina $\triangle$ 
disminuyó en 2013 , a 1,3 trillones de pies cúbicos de gas natural seco, por séptimo año consecutivo.

La regulación administrativa de los precios de la energía también ha creado enormes distorsiones en el mercado, potenciando el consumo y desalentando las inversiones. Como resultado, los precios de la electricidad son alrededor de un tercio del precio medio en los países vecinos. La diferencia en el coste del gas natural importado y el coste medio para los consumidores locales ha llegado al 1.000 por 100 . La creciente brecha ha sido cubierta por subsidios a la energía, que han aumentado a casi el 2,5 por 100 del PIB.

En otoño 2014, después de largas negociaciones entre el Gobierno federal, provincias productoras de petróleo regional, YPF y representantes del sector de petróleo y gas privado, el Congreso argentino aprobó una nueva Ley de Hidrocarburos. Ha sido un esfuerzo por abordar algunos de estos desequilibrios y hacer varias mejoras en el marco de la reglamentación para fomentar las inversiones extranjeras a largo plazo. La nueva ley ha introducido un único proceso de licitación a nivel nacional; ha aclarado los plazos de extensión del permiso de exploración; ha ampliado el tope de exportación libre de aranceles al 20 por 100 de la producción; y ha unificado los topes de royalties limitados para las provincias productoras de petróleo. Tales ajustes de política han enviado una señal positiva a los inversores, pero no van lo suficientemente lejos para revertir completamente una tendencia negativa en el sector energético.

En respuesta al deterioro del entorno exterior y al debilitamiento de las reservas financieras, las autoridades argentinas tomaron otras medidas, que deberían haber tomado antes (pero que no se tomaron porque la situación se veía mejor en aquel momento) para volver a los mercados internacionales de capital, mejorar la competitividad nacional, restablecer la estabilidad fiscal y la confianza de los inversores.

En 2014 el peso se devaluó un 20 por 100 y las subvenciones al gas y al agua también se redujeron un 20 por 100 en media. Argentina también reconoció el fallo del ICSID (International Centre for Settlement of Investment Disputes) en cinco disputas de propiedad e inversión. En este sentido, Argentina negoció un pago por compensación de 5.000 millones de dólares con Repsol por los activos nacionalizados de YPF, y acordó pagar 9.700 millones de dólares a los acreedores oficiales del Club de París en los próximos cinco años.

Todos estos esfuerzos han ayudado a romper el estancamiento en el que se encontraban las relaciones con las IFI, en particular las instituciones de Bretton Woods. El Banco Mundial había congelado la financiación de todas las operaciones en Argentina desde 2012. La aprobación de un nuevo Acuerdo de Partenariado con Argentina (Country Partnership Agreement -CPA-) también se había retrasado. La última consulta del Artículo IV del FMI en Argentina se había ido posponiendo desde 2006. En 2013, el FMI emitió una declaración de censura desafiando la metodología estadística nacional respecto al índice de precios al consumidor (IPC) y pidió una mejora en la calidad de los datos oficiales de IPC y PIB.

EI BID ha sido históricamente uno de los principales acreedores internacionales de Argentina, con unas aprobaciones anuales promedio de 1.360 millones de dólares en los últimos años. La cartera activa de proyectos del sector público incluye 54 operaciones con un valor total aprobado de unos 9.200 millones de dólares, de los cuales están pendientes de desembolsar unos 3.874 millones de dólares (42,1 por 100). La cartera está distribuida como sigue: el 61 por 100 está dedicada a proyectos que apoyan el crecimiento y la competitividad (transporte, energía, ciencia y tecnología, desarrollo agrícola y rural, turismo); el 28 por 100 en el área de desarrollo social (agua potable y saneamiento, educación, salud, desarrollo social, desarrollo urbano); y el 11 por 100 en el área de gobernanza (modernización del Estado, gestión fiscal, seguridad ciudadana). Al mismo tiempo, Argentina ha alcanzado rápidamente su techo de endeudamiento con el BID, lo que puede limitar extensos préstamos en el futuro. 
A pesar de la cautela y persistentes prejuicios existentes, Buenos Aires se ha fijado como objetivo clave volver a comprometerse con las instituciones de Bretton Woods por varias razones obvias:

- La normalización de las relaciones con el Grupo del Banco Mundial y el FMI tendrá un efecto demostración y enviará un fuerte mensaje positivo a los socios internacionales y la comunidad internacional de negocios.

- La participación del FMI en la evaluación macroeconómica, así como en las políticas monetaria y fiscal reducirá el escepticismo sobre los datos económicos sesgados a nivel local y confirmará el retorno a las normas internacionales.

- La financiación del Grupo del Banco Mundial a los sectores público y privado tiene influencia significativa y aumenta la capacidad de un país para pedir prestado en los mercados de capitales y atraer nuevos inversores privados e institucionales.

- Una implementación del proyecto suele ir acompañada de asistencia técnica y refleja la experiencia del Grupo del Banco Mundial y las mejores prácticas internacionales, contribuyendo a la creación de capacidades.

Adicionalmente, hay un interés evidente por parte de las instituciones de Bretton Woods de reanudar una interacción de pleno derecho con una de las economías más grandes de América Latina, teniendo presente las lecciones aprendidas en el pasado. La ausencia de una relación tal y la incapacidad duradera para encontrar soluciones razonables a las cuestiones bilaterales han creado un riesgo reputacional en las instituciones de Bretton Woods. Los principales grupos de interés en las instituciones de Bretton Woods han considerado un enfoque «más suave» tras los ajustes económicos realizados por Argentina y la competencia potencial de nuevas instituciones en desarrollo, como el Banco de los BRICS (Brasil, Rusia, India, China y Sudáfrica).

Esta situación empujó al Grupo del Banco Mundial a aprobar en 2014 un nuevo Acuerdo de
Partenariado con Argentina (Country Partnership Agreement -CPA-) para el periodo 2015-2018 descansando sobre tres grandes temas: la creación de empleo; la disponibilidad de activos para personas y hogares; y la reducción de los riesgos ambientales. El nuevo Acuerdo de Partenariado con Argentina prevé una nueva financiación de inversiones de unos 1.000-1.200 millones de dólares por año fiscal del Banco Mundial, mientras que la International Finance Corporation (IFC) compromete unos 1.700 millones de dólares para apoyar al sector privado. La Multilateral Investment Guarantee Agency (MIGA) también considerará las solicitudes de cobertura de las inversiones sobre una base de caso por caso.

A partir de junio de 2014, el Directorio Ejecutivo del FMI ha revisado en varias ocasiones el progreso de Argentina en el suministro de información estadística oficial, lo que refleja una mejora notable en el suministro de los datos recientes. El FMI ha expresado su disposición a continuar el diálogo bilateral y fortalecer aún más las relaciones con Argentina.

En el contexto de un continuo diálogo entre el BID y el Gobierno de Argentina, el BID ha contado siempre con una Estrategia País para Argentina. Con el fin de asegurar que las intervenciones del BID tengan el máximo impacto, Argentina y el BID acordaron una Estrategia País 2012-2015 con un enfoque geográfico en dos regiones críticas: la región del Norte Grande que muestra los niveles más bajos de desarrollo económico del país, y el Gran Buenos Aires que sufre de los mayores niveles de exclusión social y se enfrenta a grandes retos de sostenibilidad urbana.

La inminente próxima campaña electoral en Argentina ha limitado las decisiones económicas sustantivas y las ha trasladado al período posterior a las elecciones presidenciales y parlamentarias de otoño 2015. Se espera que un nuevo Gobierno reanude las negociaciones y llegue a un acuerdo con los acreedores que no entraron en el canje de deuda, lo que podría permitir a Argentina evitar un nuevo impago soberano. Todo lo $D$ 
cual sería un cambio de las reglas de juego para el futuro desarrollo económico.

\section{Argentina y Grecia: ¿similitudes o grandes diferencias?}

En este contexto actual, no son pocos los economistas que tratan de identificar similitudes entre el caso de Argentina y Grecia. Arturo C. Porzecanski, especialista en finanzas internacionales en la American University y autor de numerosos trabajos sobre el default de Argentina, destaca que el caso de Grecia «es probable que sea peor. Argentina fue relativamente afortunado", aunque no exento de serias dificultades.

Lo que produjo un fuerte deterioro de los salarios reales y la actividad económica en Argentina fue la conversión obligatoria de los activos y deudas denominados en dólares a pesos al tipo de cambio un dólar un peso. Esta conversión forzosa decretada en enero de 2002 y conocida popularmente como el «corralón» provocó un drástico ajuste fiscal y un deterioro del nivel de vida de los argentinos como consecuencia del estallido inflacionario que siguió a la devaluación masiva del peso. El colapso financiero de Argentina fue tal que uno de cada cinco argentinos se quedó sin trabajo. El peso perdió casi el 70 por 100 de su valor, y los bancos congelaron los depósitos y miles de los manifestantes, sin éxito, trataron de retirar sus ahorros de los bancos. En las protestas y saqueos de diciembre de 2001 murieron 27 personas; las manifestaciones en Grecia han resultado ser «más pacíficas».

Los que sostienen que el crecimiento de la economía argentina entre 2003 y 2013 (después de una caída de un 10 por 100 del PIB real en 2002 y una caída total del 25 por 100 del PIB real entre 1999-2002) tuvo su origen en la conversión obligatoria de dólares a pesos ignoran el hecho de que, en 2003 , Argentina tenía un sector privado competitivo, bien capitalizado e infrautilizado que había sido construido en la década anterior, y que a partir de mediados de 2002 permitió a Argentina aprovechar el tirón del crecimiento de los intercambios internacionales. La recuperación económica de Argentina fue impulsada en gran parte por un fuerte aumento de las exportaciones de productos básicos ante la demanda de países en rápido crecimiento como Brasil y China. Argentina tenía una población de más de 41 millones de habitantes y un PIB de 610.000 millones de dólares en 2013. Aunque es un importador neto de energía, Argentina tiene vastas reservas de petróleo de esquisto y gas que podrían hacerle autosuficiente. No obstante, y pese al elevado crecimiento de este período, Argentina sigue aislada de los mercados internacionales de capital y su sector privado se encuentra en desventaja debido a la persistente estanflación.

Grecia, por el contrario, no tiene el sector privado que tenía Argentina ni dispone de capacidad infrautilizada. Grecia no puede esperar un empujón económico similar de una conversión forzosa de euros a dracmas. Si Grecia sigue el mismo camino que Argentina, sufrirá décadas de mayores dificultades y estanflación. Grecia es altamente dependiente de las importaciones, principalmente de petróleo bruto y refinado y productos farmacéuticos. Mientras que su principal exportación es también petróleo refinado, tiene que importar crudo para sus refinerías. Sus únicas exportaciones destacadas de producción local son el pescado fresco y el algodón, siendo difícil aumentar significativamente las ventas de cualquiera de estos productos, ya que la UE tiene cuotas estrictas para prevenir la pesca excesiva, mientras que la producción de algodón se enfrenta a una menor demanda para textiles y a la falta de financiación bancaria. Adicionalmente, Grecia es un país pequeño, con una población de poco más de 11 millones de habitantes y un PIB de 242.000 millones de dólares en 2013.

Grecia ha impuesto controles de cambio y restricciones sobre la retirada de dinero en efectivo de sus bancos para evitar el colapso de su sistema bancario. El Banco Central Europeo (BCE) ha mantenido a los bancos griegos con vida. Sólo el $D$ 
Banco de Grecia debe al BCE más de 125.000 millones de euros para financiar las salidas de capital y las necesidades de liquidez. El BCE tiene en su posesión 27.000 millones de euros de deuda soberana griega. El sector privado (gran parte del cual financia sus actividades con los préstamos denominados en euros de bancos no griegos) no está pagando sus deudas y la mitad de los préstamos bancarios del país están en mora. Los impuestos no se pagan y la gente está acaparando euros. Como señala la economista estadounidense de origen cubano, Carmen M. Reinhart, esta situación (de control de cambios, restricciones a la retirada de dinero efectivo de los bancos, impago de deudas por el sector privado, morosidad bancaria) se produjo en Argentina en 2002 y 1989, en Perú en 1985, en Bolivia y México en 1982; todas eran economías dolarizadas bajo estrés que convirtieron forzosamente sus depósitos denominados en dólares a moneda nacional. Esta conversión forzosa vino acompañada de fuga de capitales, caída de la producción y severa contracción de la intermediación financiera nacional. Por todo ello, un acuerdo de reducción significativa de la deuda griega y la garantía del apoyo del BCE al sistema bancario griego se consideran las vías para evitar que Grecia recorra el doloroso camino que supondría abandonar el euro y reintroducir el dracma. El desafío práctico de difusión de una nueva moneda sería enorme. No es lo mismo devaluar una moneda existente que crear una nueva en un contexto de crisis.

En el mismo sentido que Carmen M. Reinhart, el exministro de Economía de Argentina, Roberto Lavagna, acreditado por desempeñar un papel clave en la recuperación de su país después del impago de la deuda en 2001, ha afirmado que la manera de ayudar a Grecia a salir de la crisis y evitar un conflicto dentro de la Unión Europea es renegociar su deuda. En la misma línea, Martin Guzmán de la Universidad de Columbia destaca que, hasta cierto punto, Grecia se enfrenta a una situación más compleja de la que vivió Argentina en 2001. El impago de Argentina fue acompañado por una gran devaluación de la moneda que hizo al país más competitivo y que, junto con la reestructuración de la deuda, sentó las bases para una recuperación económica sostenida.

Adicionalmente, es preciso resaltar que se están analizando diferentes etapas de la crisis económica y financiera, en Argentina 2002 (etapa inicial) y en Grecia 2015 (etapa de madurez). Los griegos ya han puesto en marcha un conjunto de reformas estructurales, han hecho ajustes económicos dolorosos que han permitido volver a la senda del crecimiento después de los conflictos. El precio de un «U-turn» (retirar el euro y restablecer el dracma) sería aún mayor porque significa pérdida de tiempo y mayores sacrificios para toda la sociedad.

Según estimaciones del FMl efectuadas en 2012, cualquier moneda con la que Grecia reemplace al euro reduciría su valor a la mitad rápidamente. Grecia perdería de inmediato el 8 por 100 del PIB, la inflación aumentaría un 35 por 100 y el coste de las importaciones se dispararía. La incertidumbre y la confusión reinarían, exacerbadas por los meses que tomaría a la nueva moneda entrar en circulación; las protestas sociales se multiplicarían. El precio del Grexit estaría cerca de los 340.000 millones de euros, esto es, más del 3 por 100 del PIB de la zona euro.

Grecia ha tensado la cuerda hasta el extremo con el fin de conseguir más influencia en las negociaciones para mantener a Grecia en la UE y la zona euro. No obstante, la declaración hecha por Yaris Varoufakis: «Saludo al pueblo argentino por haber derrocado a un régimen, y más de un Gobierno, que intentaba desesperadamente sacrificar un pueblo orgulloso en pro de la austeridad liderada por el FMl', pone de manifiesto que el espíritu crítico contra las instituciones de Bretton Woods sigue existiendo ${ }^{3}$. Según Porzecanski, la población de países como Venezuela y Cuba ha aguantado economías fallidas y bajos niveles de vida durante años. Todo ello demuestra que «EI populismo y el nacionalismo todavía son fuerzas potentes».

\footnotetext{
3 Lectura recomendada del artículo de Stiglitz, Joseph E. (July $1^{\text {st }}$, 2015) «Europe's Attack on Greek Democracy». Become fan. Professor at Columbia University and a Nobel Laureate.
} 
Finalmente, obligado es destacar la argumentación de algunos economistas que subrayan que Grecia tiene algo que Argentina no tuvo: un marco institucional internacional que puede ayudar a recuperar el equilibrio fiscal y externo sin la necesidad de la devaluación.

\section{Conclusión}

Los debates entre los principales candidatos en la carrera presidencial de Argentina muestran un entendimiento general de la inviabilidad económica del status quo. Sin embargo, hay diferencias significativas en cuanto al ritmo, la secuencia y la profundidad de las reformas necesarias para solventar los límites y grietas del modelo económico actual. Para hacer reformas significativas es importante contar con un nuevo presidente con mayoría parlamentaria que no pueda ser garantizada en esta etapa. Un nuevo presidente sin un fuerte respaldo del Congreso no sería capaz de llevar a cabo las reformas necesarias. Por otro lado, existe la posibilidad de las políticas populistas ineficientes emergentes de un débil marco económico regional y shocks externos internacionales que podrían alimentar el descontento social y posponer medidas muy necesarias para reducir el déficit fiscal.

Tomando todo esto en cuenta, se supone que un conjunto de ajustes graduales y correcciones de política son más propensos a ser ejecutados para reducir la intervención estatal excesiva en la economía, estabilizar la macroeconomía, reducir la monetización, unificar el tipo de cambio, y atraer inversiones. Un paquete de reformas estructurales e institucionales es una estrategia a medio o incluso largo plazo y los costes para retrasar esos esfuerzos inevitablemente serán mayores.

\section{Bibliografía}

[1] AKLN, C. Y KOSE, M.A. (2007). "Changing Nature of North-South Linkages: Stylized Facts and Explanations». IMF Working Paper WP/07/280, Washington, D.C.
[2] AMADEO, E. (2003). La Salida del Abismo. Memoria política de la negociación entre Duhalde y el FMI. Buenos Aires: Planeta.

[3] BANCO CENTRAL DE LA REPÚBLICA ARGENTINA (2013). Inversiones directas en empresas residentes. Buenos Aires, p. 5.

[4] BANCO CENTRALDE LAREPÚBLICAARGENTINA (2015). Estadísticas. Radar Macroeconómico. Buenos Aires.

[5] BID (2012). Argentina. Estrategia País.

[6] BLUSTEIN, P. (2005). And the Money Kept Rolling In (and Out): Wall Street, the IMF, and the Bankrupting of Argentina. Washington, D.C.: PublicAffairs.

[7] BONELLI, M. (2004). Un País en Deuda. La Argentina y su Imposible Relación con el FMI. Buenos Aires: Planeta.

[8] CAVALLO, D. (2015). «What can Greece learn from Argentina's experience?» World Economic Forum, julio.

[9] CEPAL (2015). Datos y Estadísticas. Santiago de Chile.

[10] CLUB DE PARIS (2014). «The Paris Club and the Argentine Republic agree to a resumption of payments and to clearance of all arrears». Press Releases.

[11] FMI (2013). «Statement by the IMF Executive Board on Argentina». Press Release No.13/33. Washington, D.C.

[12] FMI (2015). World Economic and Financial Surveys. Reginal Economic Outlook. Western Hemisphere. Northern Spring, Southern Chills. Washington, D.C., p. 39.

[13] FMI (2004). The IMF and Argentina, 1991-2001. Washington, D.C., pp. 3, 4, 7.

[14] FMI (2013). Sovereign debt restructuring - recent developments and implications for the Fund's legal and policy framework. Washington, D.C., p. 9.

[15] FMI (2014). Emerging markets in transition: growth prospects and challenges. Washington, D.C., p. 4.

[16] FMI (2014). The Fund's lending framework and sovereign debt - preliminary considerations. Washington, D.C., p. 11.

[17] FMI (2015). World Economic Outlook. Uneven growth. Short and long term factors. Washington D.C., p. 76.

[18] GRUPO DEL BANCO MUNDIAL (2014). Country Partnership Strategy for the Argentine Republic for the period FY 15-18. Washington, D.C., p. 4. $\triangleright$ 
[19] GUZMÁN, M. (2015). «Argentina Shows Greece There May Be Life After Default». Become a fan. Postdoctoral Research Fellow Columbia University GSB, julio.

[20] HÁSKEL, G. (2014). «China's purchase of Nidera divides waters among Argentine farmers». Buenos Aires Herald.

[21] INDEC (2014). El Intercambio Comercial Argentina. Exportación, importación y saldo, por zonas económicas y principales países. Años 2009-2013. Buenos Aires.

[22] INFANTE, R. y GERSTENFELD, P. (ed.) (2013). «Hacia un desarrollo inclusivo. El caso de la Argentina». Documentos de Proyectos e Investigaciones. Santiago de Chile: Comisión Economica para América Latina y el Caribe (CEPAL), p. 68.

[23] INSTITUTE OF INTERNATIONAL FINANCE. (2015). Latin America: The Year of Reckoning. Washington, D.C., p. 3.

[24] INSTITUTE OF INTERNATIONAL FINANCE. (2015). Latin America: The Year of Reckoning. Washington, D.C., p. 14.

[25] INSTITUTO NACIONAL DE ESTADÍSTICAS Y CENSOS (INEC). (2015). Estimaciones trimestrales del balance de pagos y de activos y pasivos externos de la República Argentina. Buenos Aires.

[26] INTER-AMERICAN DEVELOPMENT BANK. (2015). Argentina. Overview. Washington, D.C.

[27] INTERNATIONAL ENERGY AGENCY. (2015). Statistics for Argentina. Balances. Paris.

[28] KEDAR, C. (2012). The International Monetary Fund and Latin America. The Argentine Puzzle in Context. Temple University Press.

[29] LEY27.007-InfoLEG-MINISTERIODE ECONOMÍA Y FINANZAS (2007). Disponible en: www.inforleg.gob.ar

[30] MILLER, T. y KIM, A.B. (2015). «2015 Index of Economic Freedom. Promoting Economic Opportunity and Prosperity». The Heritage Foundation and the Wall Street Journal (en línea). Disponible en:

http://www.heritage.org/events/2015/01/2015index-launch (27 de enero 2015).

[31] MINISTERIO DE ECONOMÍA Y FINANZAS PÚBLICAS. (2012). La Macroeconomía Argentina 2003-2012. Buenos Aires. pp. 19, 22 y 27.

[32] MINSBURG, N. (2003). Los Guardianes del Dinero. Buenos Aires: Grupo Editorial Norma.
[33] MUSSA, M. (2002). Argentina and the Fund: From Triumph to Tragedy. Washington, D.C.: Grupo Editorial Planeta y World Publications, S.A.

[34] NASDAQ (2015). Latest Price \& Chart for Soybeans and Corn. Disponible en:

http://www.nasdaq.com/markets/soybean.aspx\# ixzz3aECkzMWV

http://www.nasdaq.com/markets/corn.aspx\# ixzz3aGfM8MgL

[35] PROCREAR (2015). Programa Crédito Argentino. Disponible en: www.procrear.anses.gob.ar

[36] REINHART, C. M. (2015). «What Greece Can Expect». Bloomberg View (julio).

[37] STEWART, J. B. (2015). «If Greece Defaults, Imagine Argentina, but Much Worse». The New York Times (25 de junio).

[38] STIGLITZ, J. E. (2007). «Making globalization work». The Economic and Social Review (Winter, 2008), vol. 39, $\mathrm{n}^{\circ} 3$, pp. 171-190.

[39] TENEMBAUM, E. (2004). Enemigos. Buenos Aires: Grupo Editorial Norma.

[40] THE ASSOCIATED PRESS (2015). «Argentina Recalls Its Financial Crisis, Advises Greece». The New York Times (julio).

[41] THE ECONOMIST (2012). «What Argentina tells us about Greece» (12 de febrero).

[42] THE ECONOMIST (2015). «Gradation of Grexit» (11-17 julio).

[43] THE WORLD BANK GROUP (2014). Country Partnership Strategy for the Argentine Republic for the period FY 15-18. Washington, D.C. p. 6.

[44] THUKRAL, N. y FLAHERTY, M. (2014). «China's COFCO to pay $\$ 1.5$ billion for stake in Noble's agribusiness». Reuters (en línea). Disponible en: http://reuters.es/article/idUKBREA3207K20140403 (3 de abril de 2014).

[45] UNCTAD (2011). World Investment Report. Country Fact Sheet: Argentina. Ginebra.

[46] US ENERGY INFORMATION ADMINISTRATION (2015). Argentina. International Analysis. Washington, D.C.

[47] WORLD BANK GROUP. DOING BUSINESS (2015). «Going Beyond Efficiency». Economy Rankings. Argentina. Washington, D.C.

[48] WORLD ECONOMIC FORUM (2014). The global competitiveness report 2014-2015, p. 111. 
SUSCRIPCIÓN ANUAL

\begin{tabular}{|c|c|c|c|}
\hline \multicolumn{2}{|c|}{ BOLETíN ECONÓMICO DE INFORMACIÓN COMERCIAL ESPAÑOLA (12 NÚMEROS) } \\
\hline & $\begin{array}{c}\text { ESPAÑA } \\
1 \text { año }\end{array}$ & $\begin{array}{c}\text { UNIÓN EUROPEA } \\
1 \text { año }\end{array}$ & $\begin{array}{c}\text { RESTO DEL } \\
\text { MUNDO } \\
1 \text { año }\end{array}$ \\
\hline SUSCRIPCIÓN & $65,00 €$ & $85,00 €$ & $85,00 €$ \\
\hline $\begin{array}{c}\text { Gastos de envío } \\
\text { España }\end{array}$ & $5,76 €$ & $24,36 €$ & $30,00 €$ \\
\hline $\begin{array}{c}\text { Más 4\% de IVA. } \\
\text { Excepto Canarias, Ceuta y Melilla }\end{array}$ & $2,83 €$ & & $115,00 €$ \\
\hline TOTAL & $73,59 €$ & $109,36 €$ & \\
\hline & & & \\
\hline
\end{tabular}

\section{EJEMPLARES SUELTOS}

\begin{tabular}{|c|c|c|c|}
\hline \multirow[t]{2}{*}{ BOLETÍN ECONÓMICO } & \multicolumn{3}{|c|}{ DE INFORMACIÓN COMERCIAL ESPAÑOLA } \\
\hline & $\begin{array}{l}\text { ESPAÑA } \\
1 \text { ejemplar }\end{array}$ & $\begin{array}{c}\text { UNIÓN EUROPEA } \\
1 \text { ejemplar }\end{array}$ & $\begin{array}{l}\text { RESTO DEL } \\
\text { MUNDO } \\
1 \text { ejemplar }\end{array}$ \\
\hline NÚMERO SUELTO & $7,00 €$ & $9,00 €$ & $9,00 €$ \\
\hline $\begin{array}{l}\text { Gastos de envío } \\
\text { España }\end{array}$ & $0,48 €$ & $2,03 €$ & $2,50 €$ \\
\hline $\begin{array}{c}\text { Más } 4 \% \text { de IVA. } \\
\text { Excepto Canarias, Ceuta y Melilla }\end{array}$ & $0,30 €$ & & \\
\hline TOTAL & $7,78 €$ & $11,03 €$ & $11,50 €$ \\
\hline \multicolumn{4}{|c|}{ BOLETÍN ECONÓMICO DE INFORMACIÓN COMERCIAL ESPAÑOLA } \\
\hline & $\begin{array}{l}\text { ESPAÑA } \\
1 \text { ejemplar }\end{array}$ & $\begin{array}{c}\text { UNIÓN EUROPEA } \\
1 \text { ejemplar }\end{array}$ & $\begin{array}{l}\text { RESTO DEL } \\
\text { MUNDO } \\
1 \text { ejemplar }\end{array}$ \\
\hline $\begin{array}{l}\text { NÚMERO SUELTO } \\
\text { EXTRAORDINARIO }\end{array}$ & $12,00 €$ & $15,00 €$ & $15,00 €$ \\
\hline Gastos de envío España & $0,48 €$ & $2,03 €$ & $2,50 €$ \\
\hline $\begin{array}{c}\text { Más } 4 \% \text { de IVA. } \\
\text { Excepto Canarias, Ceuta y Melilla }\end{array}$ & $0,50 €$ & & \\
\hline TOTAL & $12,98 €$ & $17,03 €$ & $17,50 €$ \\
\hline & & & \\
\hline
\end{tabular}

\section{DATOS}

Nombre y apellidos

Empresa

Domicilio

D.P.

N.I.F.

Teléf.

Email
Transferencia a la cuenta de ingresos por venta de publicaciones del Ministerio de Economía y Competitividad.

IBERCAJA. Calle Alcalá 29. 28014 MADRID (ESPAÑA) CÓDIGO CUENTA CLIENTE: 2085-9252-07-0330598330 CÓDIGO BIC DE IBERCAJA: CAZRES2Z

IBAN: ES47 2085-9252-07-0330598330
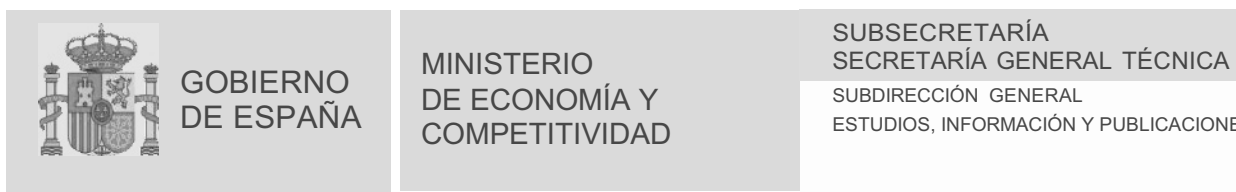

ESTUDIOS, INFORMACIÓN Y PUBLICACIONES

Suscripciones y ventas por correspondencia:

Paseo de la Castellana, 162 9ª Planta 28046 Madrid. Teléfono 91603 79 97/93

Suscripciones a través de la página web del Ministerio de Economía y Competitividad

distribucionpublicaciones@mineco.es 